\title{
British Biotech responds to allegations
}

Sir - Your News article on British Biotech continued to give credence to allegations which the company's board has repeatedly stated are "without substance or represent purely personal opinions of Dr [Andrew] Millar" (Nature 393, 299; 1998).

To provide a detailed and factual basis for this statement, the company published a 32-page circular to shareholders on 19 May. The circular was compiled with substantial due diligence and full legal verification of the information it contained. It was issued with the authority of the board of directors. In the circular, John Raisman, British Biotech's chairman, stated that, following extensive reviews, the board is satisfied "that the company has throughout acted in good faith in the interests of its shareholders and without any impropriety".

Against this background the company remains concerned that Nature may have given undue prominence to views that British Biotech directors traded in the company's shares in 1995 when they should not have done, given the status of the clinical trials of batimastat, a potential anti-cancer drug; or that they did not inform shareholders soon enough of the negative outcome of the regulatory review by the European Medicines Evaluation Agency (EMEA) of Zacutex, a potential new treatment for acute pancreatitis. These are serious allegations and they were given detailed analysis in the circular.

The facts with batimastat are clear. This injectable matrix metalloproteinase inhibitor commenced a phase III randomized controlled clinical trial in late 1994 in patients with advanced inoperable abdominal cancer. All the patients had malignant ascites, an accumulation of cancer fluid in the abdomen, and all were within months of expected death. 'Serious adverse events', the name given to any severe medical problem, were reported in these patients commonly but, importantly, at the time of the share transactions in early 1995, there was no evidence that serious adverse events were occurring more frequently in batimastat-treated patients than in the control patients not receiving the drug. Furthermore, in a previous phase II study in a similar group of patients with advanced ascites derived from ovarian cancer, batimastat had shown clinical benefits and been reasonably well tolerated.

There was therefore no reason to expect that the phase III trial would not continue as planned. In fact, as late as one week before the share transactions cited by Millar, a meeting of the London Gynaecology Oncology Group, comprised of cancer specialists undertaking the trial, concluded simply that changes to the dosing of spironolactone, a diuretic, may be necessary and that the study would be discussed again in three months' time.

As a result of reviewing these events in detail the board stated clearly in the circular that it "is satisfied there is no substance to the allegations that certain of the then directors of the company dealt in shares when they should not have done".

In relation to whether British Biotech made adequate disclosure of the progress of its marketing authorization application through the EMEA review process, the circular gives a detailed chronology of events and shows that "all public statements in relation to Zacutex were factually accurate and reflected the company's reasonable expectations of the prospects for Zacutex at the time they were made". No company can aspire to higher standards of disclosure than this.

In your editorial of 28 May (Nature 393, 291; 1998) you thank Millar for highlighting the ease with which the boundary between hope and hype can break down, with the implication that this situation applies to Zacutex. However, a large-scale (1,500-patient) international trial of Zacutex in acute pancreatitis is still under way. The outcome of this double- blind pivotal study, expected at the end of 1998, cannot be predicted at this stage. It is designed to confirm whether Zacutex, a platelet activating factor antagonist, can reduce mortality in the treatment of acute pancreatitis as suggested by a previous UK phase III study. If successful, Zacutex may represent a significant breakthrough in the treatment of this disease.

However, as a result of Millar's repeated unauthorized unblinding of the data being collected in this study, in contravention of good clinical practice guidelines and all normal company and regulatory agency procedures, the integrity of this study may have been jeopardized such that it cannot be used for regulatory approval of the drug, even if the results of the trial are positive. British Biotech recently commissioned an external regulatory audit of all double-blind trials conducted by the company under Millar's supervision during his period at the company. The audit findings have shown that not only the Zacutex study but also one of the company's pivotal trials with marimastat, a potentially important new anti-cancer agent, may have been damaged in this way. Such unprofessional conduct by a senior medical executive would more normally attract condemnation rather than thanks.

It is regrettable that the events of the last few months at British Biotech have damaged the reputation and value of one of Europe's leading biotech businesses. Biotech companies are uniquely vulnerable to investor sentiment irrespective of whether this is based on scientific data or unsubstantiated rumour. Keith McCullagh (Chief Executive) British Biotech, Watlington Road, Oxford OX4 5LY, UK.

When writing the story, many attempts were made to contact McCullagh, via the company switchboard and through British Biotech's public relations officer. The calls were not returned. - Editor, Nature.

\section{Way forward atNSF}

Sir-A recent News story by Colin Macilwain implies that the US Government Performance and Results Act (GPRA) will prompt National Science Foundation (NSF) staff to look over the shoulders of grant recipients in an unprecedented way (Nature $393,100 ; 1998)$. The foundation has always required grant recipients to report on annual progress and to provide final project reports. Rather than monitoring grants more intensely, we will simply be capturing this information in a way more useful for reporting on performance of our programmes.

We are also asking for the help of grant recipients in identifying less immediately obvious effects of their activities, and to communicate those in terms that lay readers can understand.

For GPRA, NSF will examine and report on the performance of programmes as a whole, rather than the performance of individual grants. Processes are already in place in some directorates to obtain summary information on programme activities. GPRA requires that we obtain that information in a way that can be aggregated to the level of NSF as a whole and prepared for assessment by panels of external experts. We are attempting to structure this aspect of GPRA so that it has minimal impact on NSF staff and the community.

Judy Sunley (Assistant to the Director for Science Policy and Planning)

National Science Foundation, 4201 Wilson Boulevard, Arlington, Virginia 22230, USA e-mail:jsunley@nsf.gov 